\title{
NĂNG SUÂTT SINH HỌC CỦA QUẦN XÃ PLANKTON Ở VÙNG BIỂN QUẦN ĐẢO TRUOỜNG SA
}

\author{
Nguyễn Ngọc Tiến ${ }^{1 *}$, Dư Văn Toán ${ }^{2}$ \\ ${ }^{1}$ Viện Địa chất và Địa vật lý Biển-Viện Hàn lâm Khoa học và Công nghệ Việt Nam \\ ${ }^{2}$ Tổng cục Biển và Hải đảo Việt Nam, Việt Nam \\ "E-mail: nntien@imgg.vast.vn
}

Ngày nhận bài: 7-8-2013

TÓM TÁT: Năng suất sinh học của quần xã Plankton vùng biển Truờng Sa Việt Nam (6-12 ${ }^{\circ}$, 109-118 E) được tính toán trên cơ sở các hệ số chuyển hoá năng luợng giũua các bậc dinh duõng. Các hệ số này được tìm tù việc giải bài toán mô hình chu trình chuyển hoá Nito trong hệ sinh thái vùng biển nghiên cứu. Kết quả cho thấy:

Trong mùa gió Đông Bắc và mùa gió Tây Nam, năng suất sơ cấp thô có giá trị cõ $69 \mathrm{mgC/m3/ngày,} \mathrm{trong} \mathrm{đó} \mathrm{sản} \mathrm{phẩm} \mathrm{tinh} \mathrm{chiếm} \mathrm{khoảng} \mathrm{40 \% .} \mathrm{Khả} \mathrm{năng} \mathrm{tổng} \mathrm{hợp} \mathrm{vật} \mathrm{chất} \mathrm{hưu} \mathrm{co} \mathrm{ơ}$ khu vục biển phía Nam vùng nghiên cứu cao hơn khu vục biển phía Bắc.

Năng suất sơ cấp tinh của vùng biển đạt cỡ 24 đến 28 mgC/m3/ngày trong mùa gió Đông Bắc và mùa gió Tây Nam. Phân bố của năng suất sơ cấp có liên quan mật thiết với truờng nhiệt của vùng biển trong các mùa. Hệ số chuyển hoá năng luợng tụ nhiên ở vùng biển có giá trị 2,5\%.

Năng suất thứ cấp của vùng biển biến đổi trong khoảng 3,6 đến 4,0 mgC/m3/ngày, nhỏ hơn năng suất sơ cấp khoảng 100 lần. Năng suất thư cấp trong mùa gió Đông Bắc và mùa gió Tây Nam phân bố tuơng đối đồng đều, xu huớng tăng dần tù̀ bờ ra khoi trên vùng biển.

Tù̀ khóa: Quần xã, sinh học, plankton.

\section{MỞ ĐÀ̀}

Vùng biển quần đảo Trường Sa đóng vai trò quan trọng trong chiến lược phát triển kinh tế và an ninh quốc phòng của nước ta, cần được bảo vệ và củng cố. Thông tin chi tiết về các yếu tố hệ sinh thái như thực vật nổi, động vật nổi, năng suất sinh học, trữ lượng tiềm năng và khả năng khai thác nguồn lợi cá nổi nhỏ đặc biệt cần thiết đối với việc quản lý và bảo vệ̉ biển đảo, tiếp cận đảo. Khi không có số liệu quan trắc hoặc có rất ít, các mô hình toán học là giải pháp hữu ích trong trường hợp này. Với nỗ lực chi tiết hóa khu vực, áp dụng kỹ thuật giải và lập trình, bức tranh về hệ sinh thái vùng biển quần đảo Trường $\mathrm{Sa}$ phần nào được sáng tỏ. Kết quả tính toán sẽ cung cấp các thông tin tham khảo cho các mục đích khác nhau.

Bài báo giới thiệu các kết quả tính toán và những nhận định chủ yếu về sự phân bố, biến đổi mùa của sinh khối thực vật nổi, động vật nổi, năng suất sinh học sơ cấp và thứ cấp nói chung còn về trữ lượng tiềm năng. Đây là nghiên cứu được hoàn thành với sự hố trợ kinh phí của Viện Hàn lâm Khoa học và Công nghệ Việt Nam năm 2013.

\section{TÀI LIỆU VÀ PHƯƠNG PHÁP}

Đã tiến hành tính toán năng suất sinh học sơ cấp của thực vật nổi và năng suất sinh học thứ cấp của động vật nổi dựa vào mô hình chu trình chuyển hóa Nitơ trong hệ sinh thái 
biển. Cơ sở phương pháp luận và các quá trình chuyển hoá trong chu trình được diễn tả như sau (hình 1):

Quá trình chuyển hoá 1: Quang hợp của Phytoplankton.

Quá trình chuyển hoá 2: Hô hấp của Phytoplankton.

Quá trình chuyển hoá 3: Dinh dưỡng của Zooplankton.
Quá trình chuyển hoá 4: Hô hấp của Zooplankton.

Quá trình chuyển hoá 5 và 6: Chết tự nhiên của quần thể Phytoplankton và Zooplankton. hữu cơ

Quá trình chuyển hoá 7: Khoáng hoá chất

Quá trình chuyển hoá 8: Đạm hoá (Nitrification) và quá trình chuyển hoá 9: Phi đạm hoá (Denitrification).

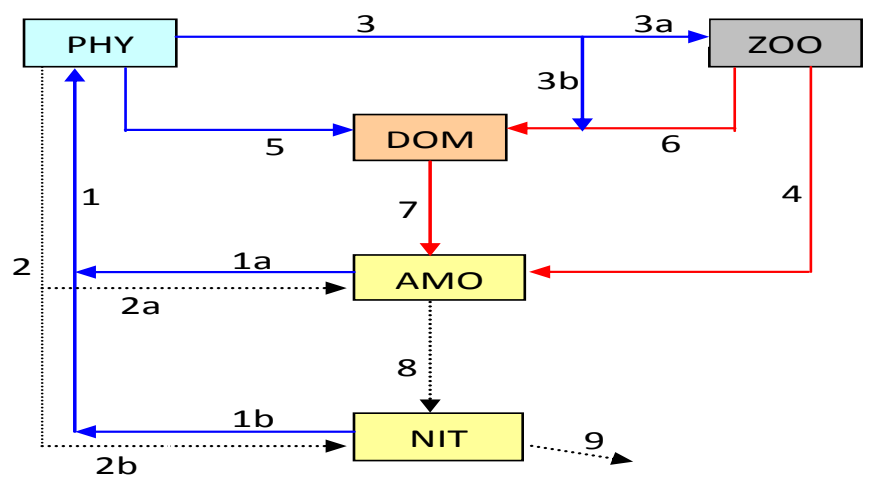

Trong đó:

PHY: Phytoplankton

ZOO: Zooplankton

DOM: Chất hữu cơ hoà tan

AMO: Amoni

NIT: Nitrat

1... 9: Các quá trình chuyển hoá

$\longrightarrow$ : H oóng chuyển hoá

Hình 1. Sơ đồ chu trình chuyển hóa Nitơ trong hệ sinh thái biển

Theo nguyên lý bảo toàn, tốc độ toàn phần biến đổi sinh khối hoặc nồng độ của một hợp phần sinh, hoá học nào đó chính là tổng đại số tốc độ các quá trình sản sinh làm tăng (nguồnProduction) và phân huỷ làm suy giảm (phân huỷ-Destruction) nồng độ hoặc sinh khối của hợp phần đó. Gọi $\mathrm{Ci}$ là nồng độ (hoặc sinh khối) của hợp phần i, Prodi, Desti tương ứng là tốc độ các quá trình làm tăng và làm giảm nồng độ của hợp phần, ta có:

$$
\frac{d C^{i}}{d t}=\operatorname{Pr} o d^{i}-D e s t^{i}
$$

Ở đây $\mathrm{i}=1, \ldots, 5$ tương ứng là $\mathrm{PHY}, \mathrm{ZOO}$, DOM, AMO, NIT.

Từng hợp phần của chu trình Nitơ, biểu thức mô phỏng Prodi, Desti như sau [2]:

$$
\begin{gathered}
\operatorname{Pr}{ }^{P} P H Y=L(i) \cdot L^{*}(\xi)\left[\frac{\delta_{A}^{P} \cdot A M O}{C_{A}+A M O}+\frac{\delta_{N}^{P} N I T}{C_{N}+N I T} \operatorname{Exp}(-\lambda . A M O)\right] . P H Y \\
D^{P}{ }^{P H Y}=F_{P}^{N} \cdot P H Y+\frac{\delta_{P}^{Z} \cdot P H Y}{C_{P}+P H Y} Z O O+F_{P}^{D} \cdot P H Y \\
\operatorname{Pr} o d^{Z O O}=\left(1-X_{P}\right) \frac{\delta_{P}^{Z} P H Y}{C_{P}+P H Y} Z O O
\end{gathered}
$$




$$
D e s t^{Z O O}=\left(F_{Z}^{A}+F_{Z}^{D}\right) Z O O
$$

$$
\begin{gathered}
\operatorname{Prod}{ }^{D O M}=\frac{X_{P} \delta_{P}^{Z} P H Y Z O O}{C_{P}+P H Y}+F_{P}^{D} \cdot P H Y+F_{Z}^{D} Z O O \\
D e s t{ }^{D O M}=F_{D}^{A} \cdot D O M
\end{gathered}
$$

$$
\begin{aligned}
& \operatorname{Pr} o d^{A M O}=F_{Z}^{A} Z O O+F_{D}^{A} D O M+\alpha_{A M O} F_{P}^{N} P H Y \\
& D{ }^{A} A M O=L(i) \cdot L(\xi) \frac{\delta_{A}^{P} A M O}{C_{A}+A M O} P H Y+F_{A}^{N} A M O \\
& \operatorname{Pr} o d^{N I T}=F_{A}^{N} A M O+\alpha_{N I T} F_{P}^{N} P H Y \\
& D e s t^{N I T}=L(i) \cdot L(\xi) \frac{\delta_{N}^{P} N I T}{C_{N}+N I T} \operatorname{Exp}(-\lambda A M O) \cdot P H Y+F_{N}^{O} N I T
\end{aligned}
$$

Mô hình toán chu trình chuyển hoá Nitơ được viết lại ở dạng tổng quát sau:

$$
\frac{d C^{i}}{d t}=\operatorname{Pr} o d^{i}-D e s t^{i}
$$

Đây là hệ phương trình vi phân thường gồm 5 phương trình, có thể giải bằng nhiều phương pháp, ở đây chọn phương pháp Runger Kuta với điều kiện ban đầu:

$$
\mathrm{C}^{\mathrm{i}}\left(\mathrm{t}=\mathrm{t}_{0}\right)=\mathrm{C}^{\mathrm{i} *} \text { (biết trước) }
$$

Kết quả của mô hình (12) với điều kiện (13) cho ta biến động theo thời gian của sinh khối, hàm lượng các hợp phần, cùng năng suất sinh học sơ cấp, thứ cấp và các hiệu quả sinh thái của vùng biển.

Với mục đích nghiên cứu hiện trạng phân bố các hợp phần trong chu trình Nitơ và các đặc trưng của các quá trình sản xuất vật chất hữu cơ bậc thấp ở vùng biển tại một thời điểm nào đấy, bài toán (12) được giải trong điều kiện dừng $\left(\mathrm{dC}^{\mathrm{i}} / \mathrm{dt}=0, \mathrm{i}=1 \ldots 5\right)$, nghĩa là:

$$
\text { Prodi }- \text { Desti }=0, i=1, \ldots, 5
$$

Các tài liệu sử dụng trong tính toán bao gồm: Nhiệt độ lớp nước mặt trung bình nhiều năm mùa đông và mùa hè. Dũ liệu này được tính toán thống kê trên các ô 0,25 độ kinh vĩ tại vùng biển nghiên cứu, nguồn từ Ủy ban Đại dương và khí quyển (NOAA) phát hành năm 2009 [7].

Cường độ bức xạ được tính toán từ các điều kiện thiên văn trung bình trên các vĩ độ ở vùng biển nghiên cứu trong các mùa đặc trưng.

Các tham số sinh thái trong mô hình được lựa chọn phù hợp với điều kiện biển nhiệt đới Việt Nam và vùng biển nghiên cứu được thể hiện ở bảng 1 [4-6].

Trường độ sâu tính toán từ lớp mặt đến $200 \mathrm{~m}$ nơi bức xạ quang hợp có thể tới. 
Bảng 1. Một số thông số (hằng số) chính sử dụng trong mô hình và giá trị lựa chọn cho vùng biển Trường $\mathrm{Sa}$

\begin{tabular}{|c|c|c|c|c|}
\hline TT & Ký hiệu & Thông số & Thứ nguyên & Giá trị \\
\hline 1 & $\delta_{N}^{P}$ & Tốc độ riêng cực đại sử dụng Nitrat trong quang hợp & $(\text { Ngày })^{-1}$ & 2,2 \\
\hline 2 & $\delta_{A}^{P}$ & Tốc độ riêng cực đại sử dụng Amoni trong quang hợp & $(\text { Ngày })^{-1}$ & 1,8 \\
\hline 3 & $P A R_{O P T}$ & Cường độ sáng thích hợp cho quang hợp & $\mathrm{W} / \mathrm{m}^{2}$ & 120 \\
\hline 4 & $\beta_{\mathrm{T}}$ & Hệ số biểu thị ức chế quang hợp do nhiệt độ & - & $-0,5$ \\
\hline 5 & $\beta_{\text {। }}$ & Hệ số biểu thị ức chế quang hợp do ánh sáng & - & $-0,5$ \\
\hline 6 & $T_{\text {Leth }}$ & Cận dưới nhiệt độ quang hợp & ${ }^{\circ} \mathrm{C}$ & 16 \\
\hline 7 & TOPT & Nhiệt độ tối thuận cho quang hợp & ${ }^{\circ} \mathrm{C}$ & 28 \\
\hline 8 & $\lambda$ & $\begin{array}{l}\text { Hệ số biểu thị sự ức chế tác dụng của NIT trong quang hợp khi có } \\
\text { AMO }\end{array}$ & $(\mu \mathrm{AT}-\mathrm{gN} /)^{-1}$ & 1,5 \\
\hline 9 & $\mathrm{~N}_{\mathrm{m}}$ & $\begin{array}{l}\text { Giá trị nghưởng Nitơ tổng (AMO+NIT) tại đó cường độ chết của } \\
\text { PHY đạt cực đại }\end{array}$ & $\mu \mathrm{AT}-\mathrm{gN} / \mathrm{l}$ & 0,3 \\
\hline 10 & $\mathrm{C}_{\mathrm{P}}$ & Hệ số bán bảo hoà hàm lượng thức ăn & $\mu \mathrm{AT}-\mathrm{gN} / \mathrm{l}$ & 0,5 \\
\hline 11 & $\mathrm{PHY}_{\mathrm{m}}$ & $\begin{array}{l}\text { Giá trị nghưỡng của lượng thức ăn PHY tại đó cường độ chết của } \\
\text { ZOO cực đại }\end{array}$ & $\mu \mathrm{AT}-\mathrm{gN} / \mathrm{I}$ & 1,0 \\
\hline 12 & $\delta_{Z}^{A}$ & Tốc độ riêng bài tiết Amoni tại $0^{\circ} \mathrm{C}$ & $(\text { Ngày })^{-1}$ & 0,1 \\
\hline 13 & $b_{e}$ & Hệ số biểu thị ảnh hưởng nhiệt độ đến tốc độ bài tiết & - & 1,03 \\
\hline 14 & $\delta_{D}^{A}$ & Tốc độ riêng phân huỷ thành Amoni tại $20^{\circ} \mathrm{C}$ & $(\text { Ngày })^{-1}$ & 0,8 \\
\hline 15 & $\mathrm{~K}_{\mathrm{T}}$ & Hệ số biểu thị ảnh hưỡng của nhiệt độ đến $\delta_{D}^{A}$ & - & 1,05 \\
\hline 16 & $\mathrm{~K}_{\mathrm{AMO}}$ & Tốc độ riêng đạm hoá chuyển Amoni thành Nitrat & - & 0,088 \\
\hline 17 & $\mathrm{~K}_{\mathrm{NIT}}$ & Tốc độ riêng phi đạm hoá chuyển Amoni thành Nitrat & - & 0,0001 \\
\hline 18 & $\mathrm{l}_{0}$ & Hằng số mặt trời & $\mathrm{W} / \mathrm{m}^{2}$ & 1.353 \\
\hline
\end{tabular}

\section{KẾT QUẢ VÀ PHÂN TÍCH}

\section{Đặc trưng phân bố quá trình sản xuất sơ cấp của thực vật nổi}

Trong mùa gió Đông Bắc và Tây Nam, xu hướng phát triển của thực vật nổi tại vùng biển quần đảo Trường $\mathrm{Sa}$ tăng dần từ bờ ra khơi, sinh khối của thực vật nổi ở khu vực này đạt khoảng $1.131-1.167 \mathrm{mg}$-tươi $/ \mathrm{m}^{3}$ trung bình 1.149 mg-tươi $/ \mathrm{m}^{3}$ (hình 2, 3).

So với các thời kỳ khác trong năm ở vùng vĩ độ cao và gần bờ thì mùa đông không phải là thời kỳ phát triển của thực vật nổi do nhiệt độ nước giảm thấp, cường độ bức xạ không lớn, nhưng ở vùng quần đảo Trường $\mathrm{Sa}$, mùa đông và mùa hè nhiệt độ chỉ dao động trong khoảng từ 24 đến $30^{\circ} \mathrm{C}$, các nguồn dinh dưỡng từ lục địa không có, lớp nước mặt lại có bức xạ lớn vì vậy mà sinh vật đã phát triển ở các tầng nước có bức xạ thích hợp và lượng dinh dưỡng cao. Xu thế và sinh khối thực vật nổi khá đồng đều bởi tốc độ tổng hợp chất hữu cơ và quang hợp của thực vật nổi phụ thuộc vào bức xạ mặt trời và phát triển trong ngưỡng quang hợp cho phép, đây là những điều kiện sinh thái thuận lợi cho quá trình tổng hợp chất hữu cơ của thực vật nổi trong vùng biển nghiên cứu phát triển.

Theo đó năng suất sơ cấp tinh trong gió mùa Đông Bắc và Tây Nam tại tầng mặt có xu thế và định lượng đồng đều nhau, giá trị trong hai mùa biến đồi từ 24 đến $28 \mathrm{mgC} / \mathrm{m}^{3} /$ ngày (hình 4,5 ), phân bố với xu thế tăng dần từ Nam lên Bắc. Toàn vùng biển có năng suất sơ cấp tinh đạt trung bình $26 \mathrm{mgC} / \mathrm{m}^{3} /$ ngày, riêng khu vực ở vĩ độ 12 có năng suất sơ cấp tinh cao, đạt khoảng $28 \mathrm{mgC} / \mathrm{m}^{3} /$ ngày. Điều này liên quan chặt chẽ tới các điều kiện sinh thái thuận, trong đó có nền nhiệt.

Phân bố sức sản xuất sơ cấp tinh vùng biển có đặc điểm là khu vực phía Bắc cao hơn hẳn khu vực phía Nam, năng suất sơ cấp tinh thường đạt cực đại ở tầng mặt đến tầng $50 \mathrm{~m}$. 
Nguyễn Ngọc Tiến, Dư Văn Toán

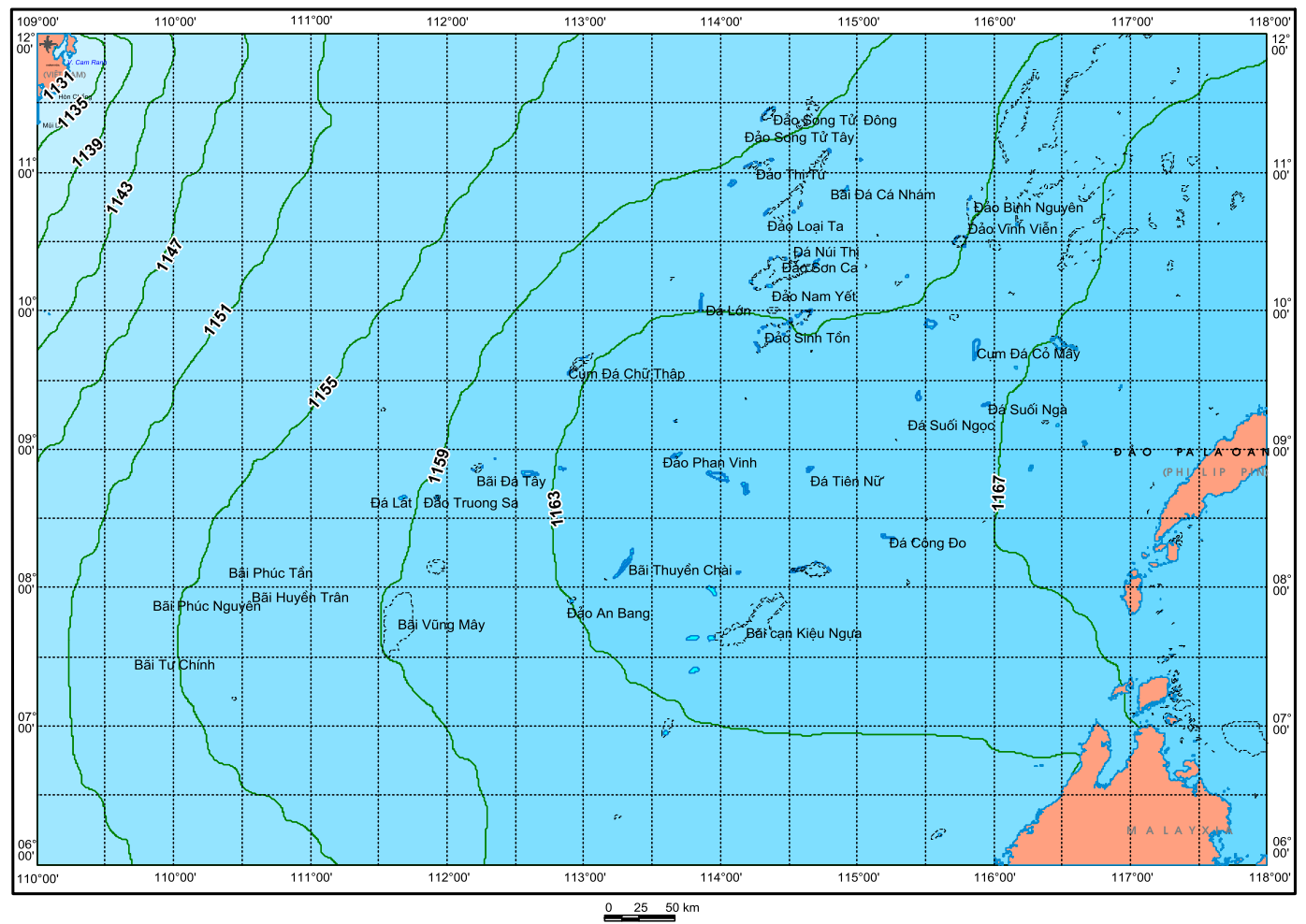

Hình 2. Phân bố sinh khối thực vật nổi $\left(\mathrm{mg}\right.$-tươi $\left./ \mathrm{m}^{3}\right)$ tầng mặt trung bình tháng 1

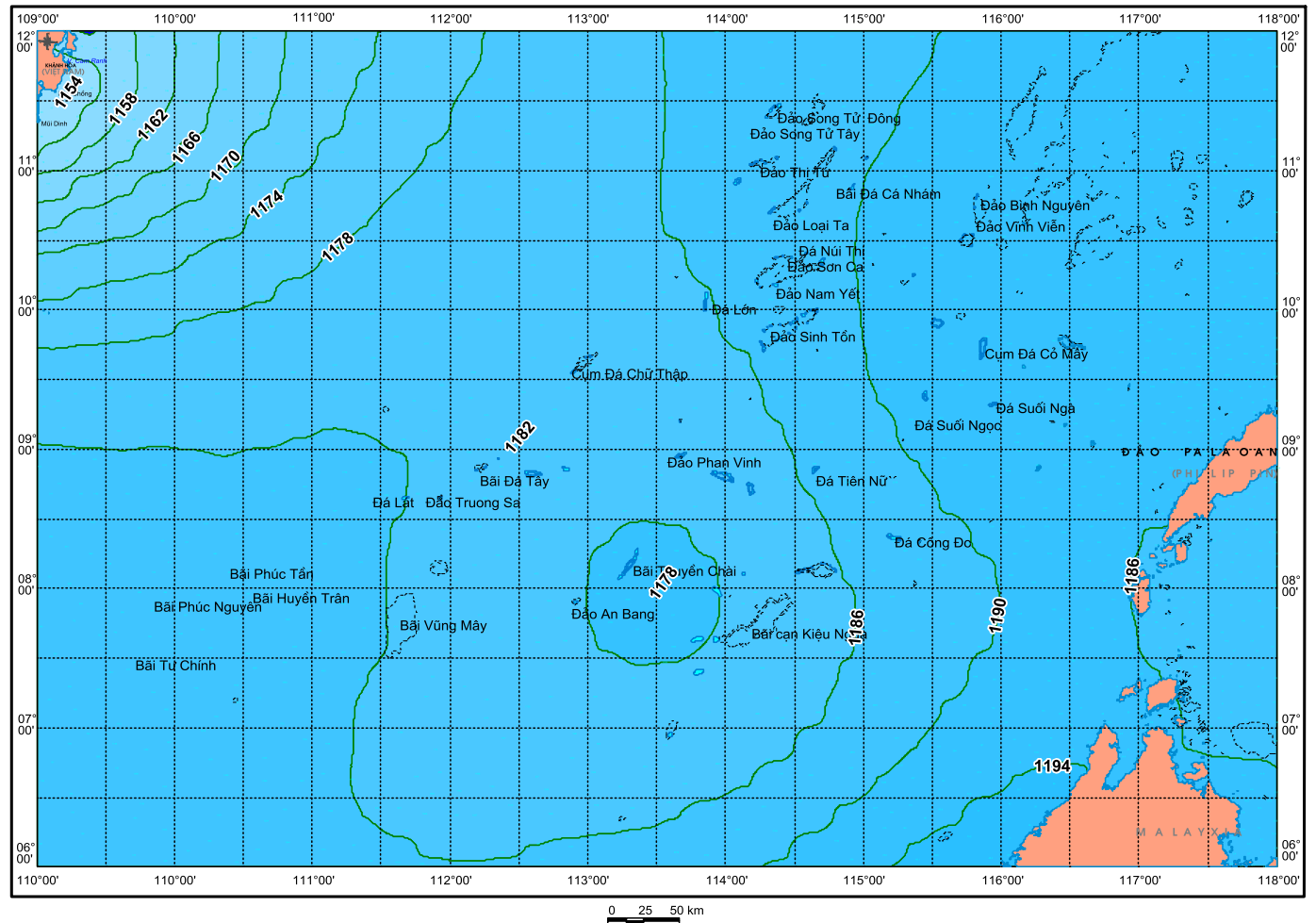

Hình 3. Phân bố sinh khối thực vật nổi $\left(\mathrm{mg}\right.$-tươi $\left./ \mathrm{m}^{3}\right)$ tầng mặt trung bình tháng 7 
Năng suất sinh học của quần xã plankton ...

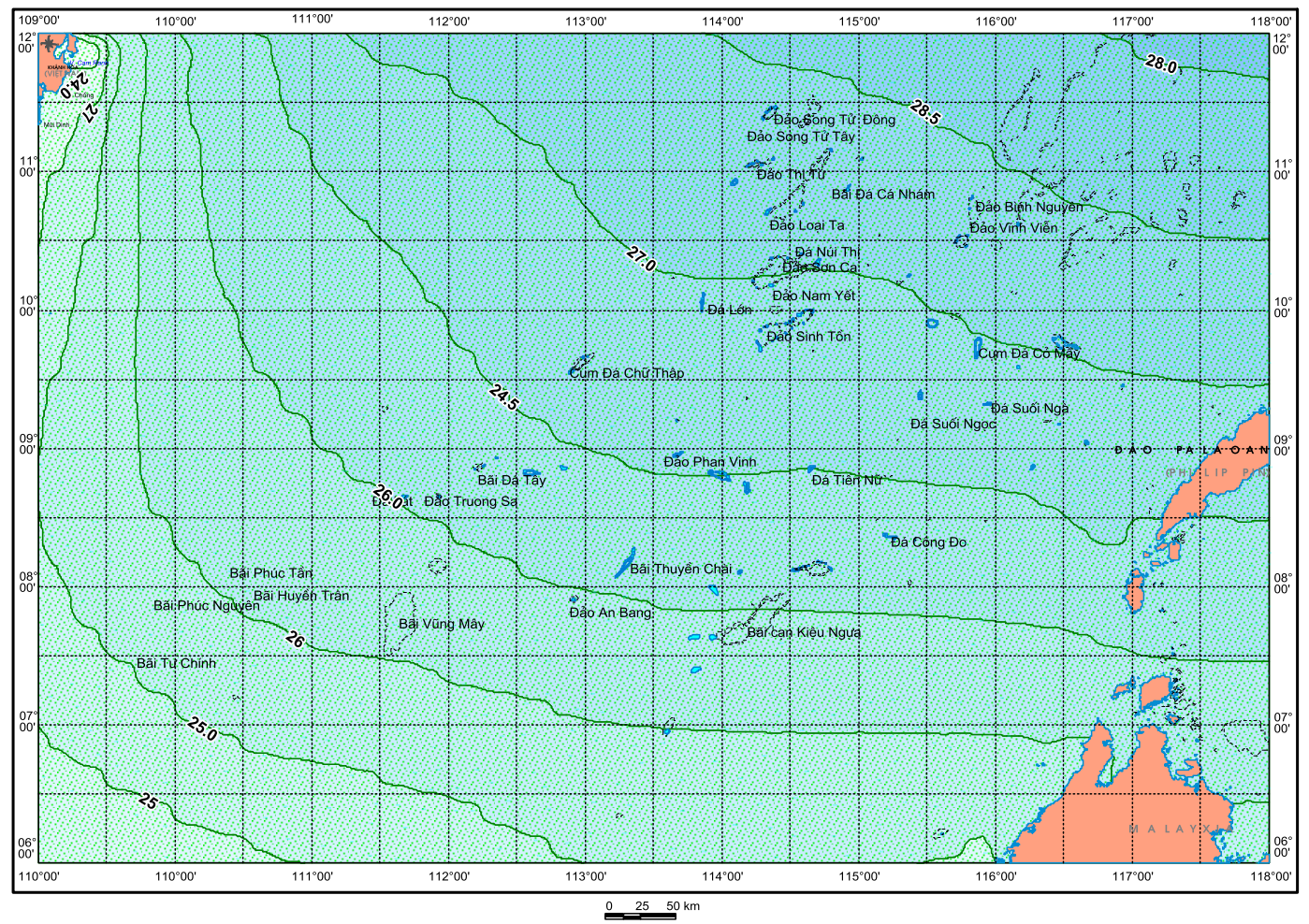

Hình 4. Phân bố năng suất sơ cấp tinh $\left(\mathrm{mgC} / \mathrm{m}^{3} /\right.$ ngày) tầng mặt trung bình tháng 1

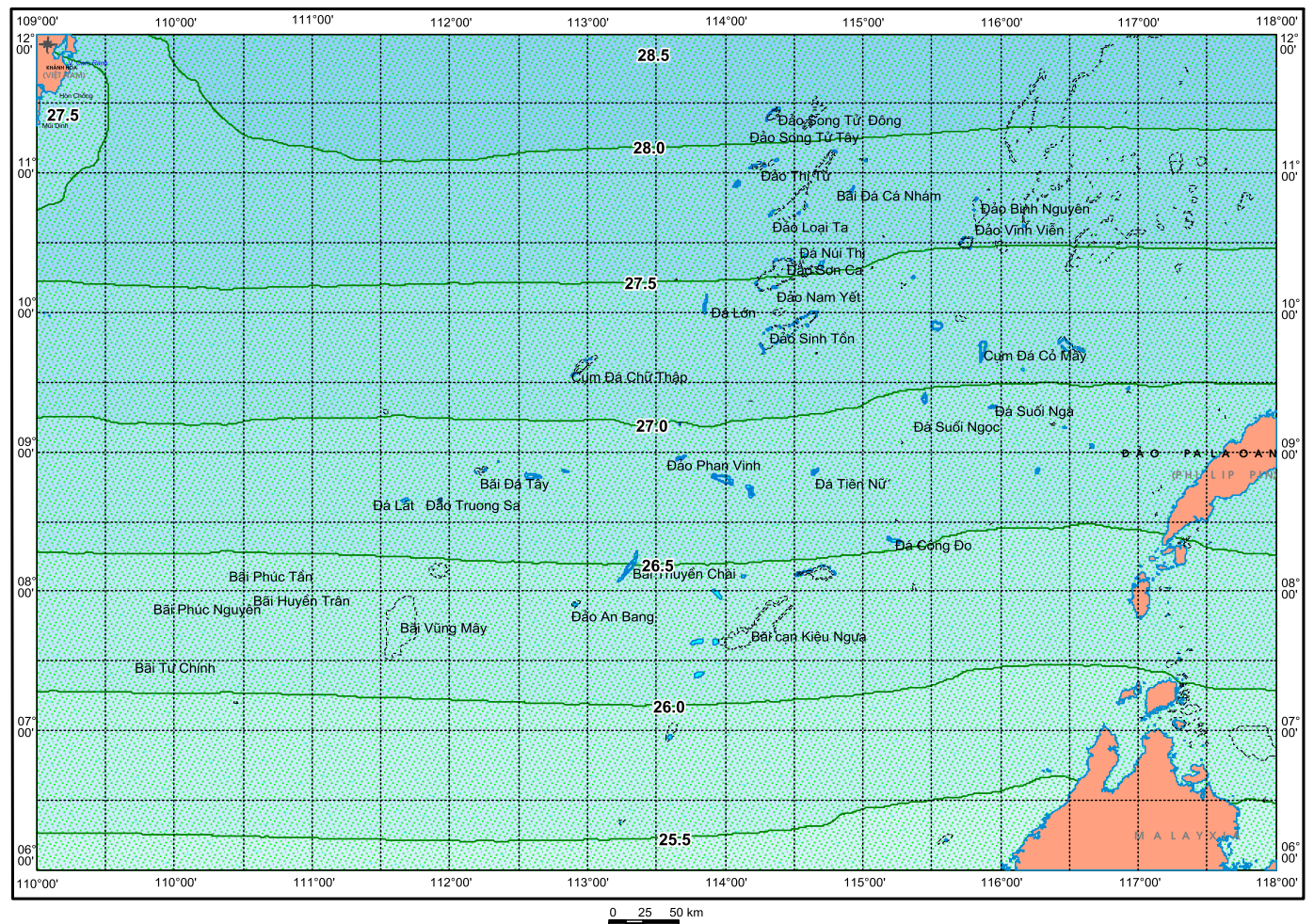

Hình 5. Phân bố năng suất sơ cấp tinh $\left(\mathrm{mgC} / \mathrm{m}^{3} /\right.$ ngày) tầng mặt trung bình tháng 7 
Nguyễn Ngọc Tiến, Dư Văn Toán

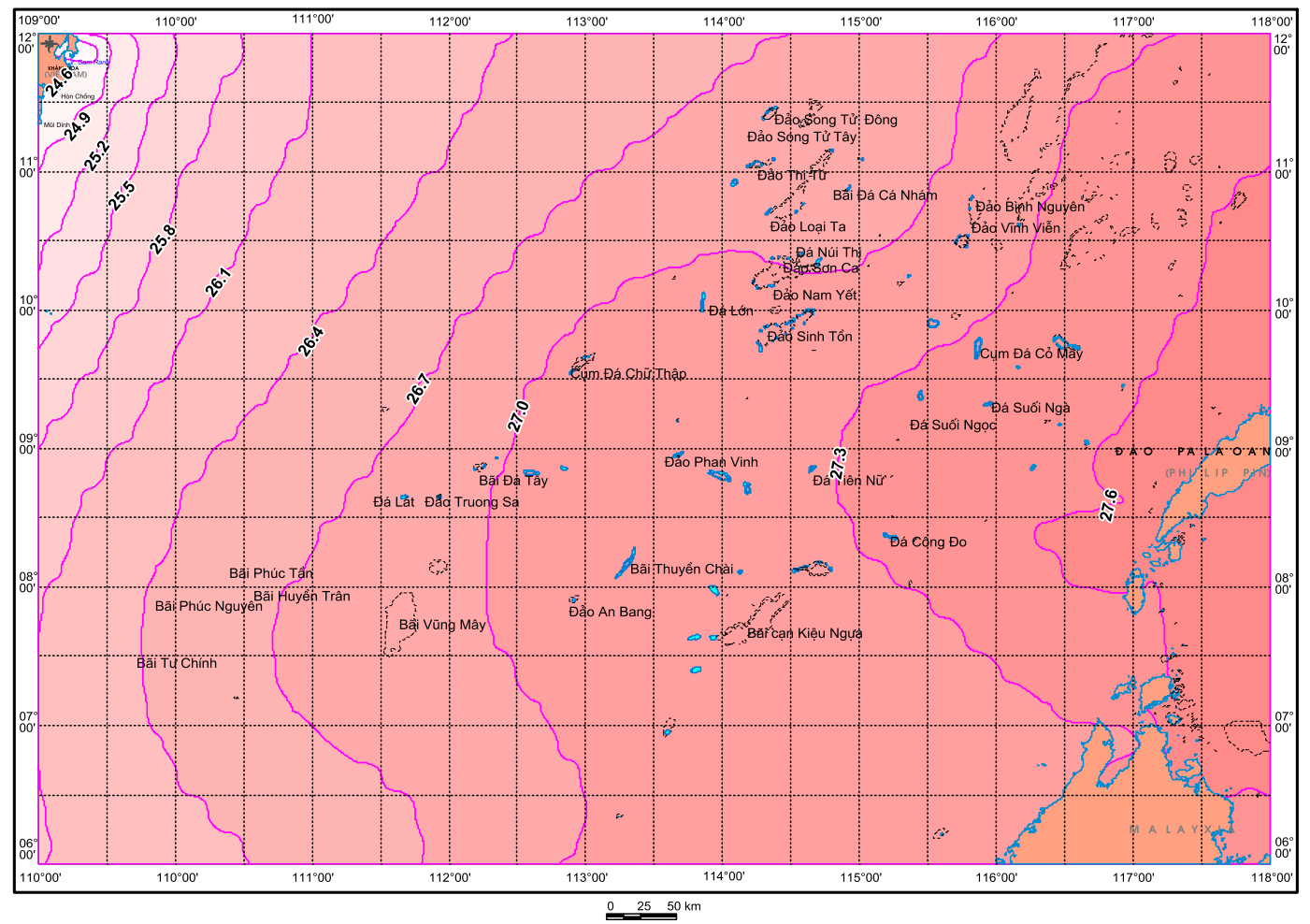

Hình 6. Phân bố nhiệt độ tầng mặt trung bình tháng 1

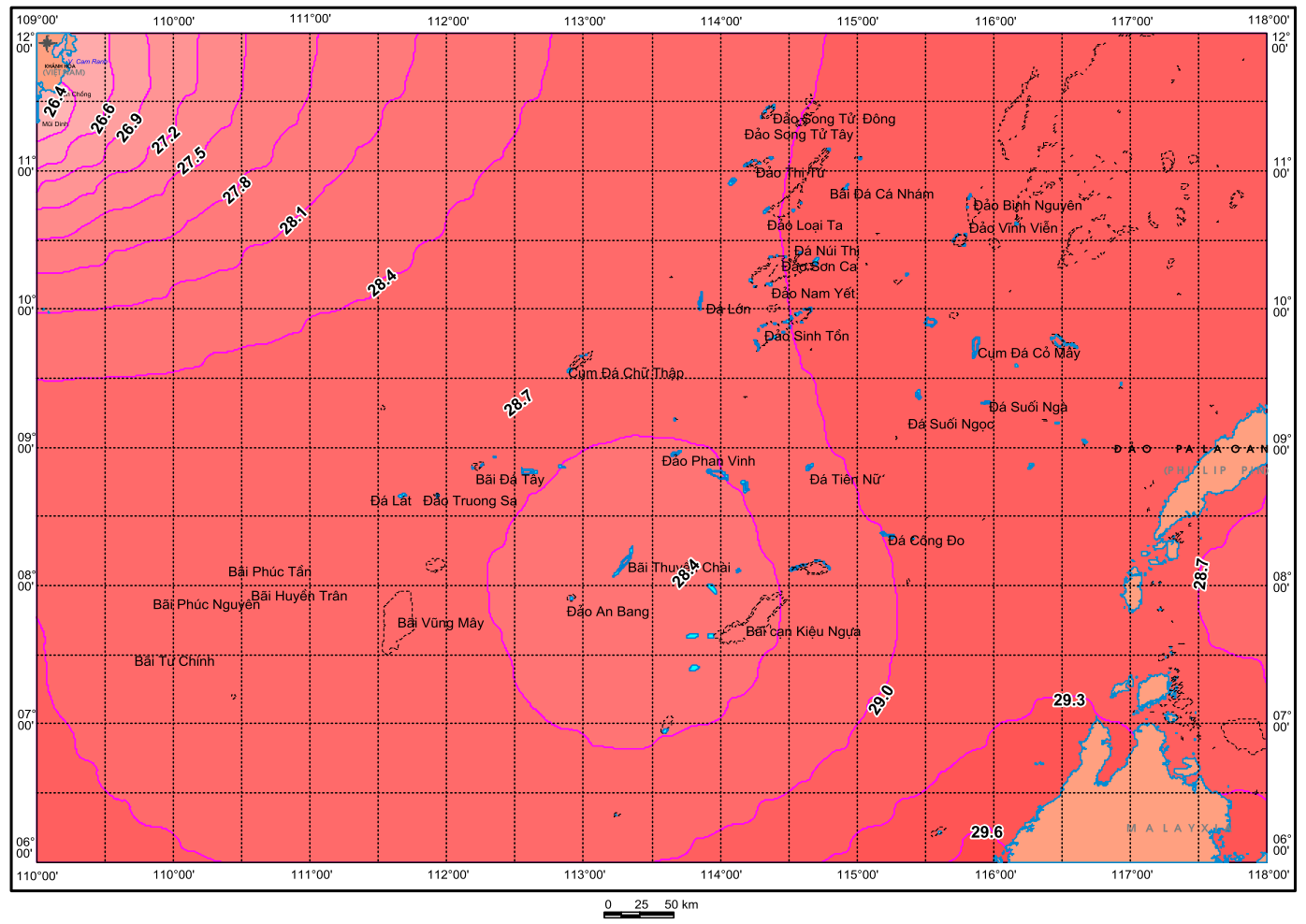

Hình 7. Phân bố nhiệt độ tầng mặt trung bình tháng 7 
Trong mùa gió Tây Nam, hầu hết các khu vực của vùng biển nghiên cứu có năng suất sơ cấp tinh trong khoảng $42-48 \mathrm{mgC} / \mathrm{m}^{3} /$ ngày, cao hơn so với mùa gió Đông Bắc và cũng đồng nhất hơn. Tuy vậy cũng có thể thấy khu vực biển Khánh Hoà, Phan Thiết và Trường $\mathrm{Sa}$ có tốc độ tổng hợp chất hữu cơ cao hơn các khu vực khác.

Xem xét đặc trưng phân bố trường nhiệt tháng 1 và tháng 7 (đại diện cho mùa gió Đông Bắc và mùa gió Tây $\mathrm{Nam}$ ), thấy rằng:

Nhiệt độ nước bề mặt biển phụ thuộc vào bức xạ mặt trời tới mặt nước biển Theo một số nghiên cứu trước đây, nhiệt độ thích hợp cho quang hợp của thực vật nổi vùng biển Nhiệt Đới Việt Nam trong khoảng $26-28^{\circ} \mathrm{C}[3,4]$. So sánh nền nhiệt trung bình mùa ở vùng biển nghiên cứu với giá trị này thấy rằng trong mùa gió Đông Bắc toàn khu vực Trường $\mathrm{Sa}$ từ vĩ tuyến $6-12^{\circ} \mathrm{N}$ có nhiệt độ nước tầng mặt đạt $26-28,5^{\circ} \mathrm{C}$ (trừ dải nước sát bờ Vũng Tàu), trong khi nền nhiệt trung bình trong mùa gió Tây Nam thường cao hơn $29,5^{\circ} \mathrm{C}$ (hình 6,7 ).

\section{Đặc trưng phân bố quá trình sản xuất sơ cấp của động vật nổi}

Trong mùa gió Đông Bắc, nét tương đồng giữa bức tranh phân bố sinh khối và năng suất của động vật nổi thể hiện khá rõ (hình 8 ) và rất phù hợp với phân bố của sức sản xuất sơ cấp của thực vật nổi, nhất là đối với sản phẩm tinh. Đây là sự biểu hiện rõ nhất và đúng quy luật về quan hệ dinh dưỡng bậc thấp ở vùng biển nghiên cứu. Xu hướng phát triển là tăng dần từ bờ ra khơi [1]. Sinh khối động vật nổi tầng mặt đạt giá trị trong khoảng $180-243 \mathrm{mg}$-tươi $/ \mathrm{m}^{3}$, trung bình $211 \mathrm{mg}$-tươi $/ \mathrm{m}^{3}$.

Trong mùa gió Tây Nam sinh khối động vật nổi (hình 9) dao động trong khoảng 227 $267 \mathrm{mg}$-tươi $/ \mathrm{m}^{3}$.

Xu thế chung phân bố theo mặt rộng của động vật nổi mùa gió Tây Nam và Đông Bắc tại quần đảo Trường $\mathrm{Sa}$ là tăng dần từ bờ ra khơi và xu thế biến đổi tương đối đồng đều.

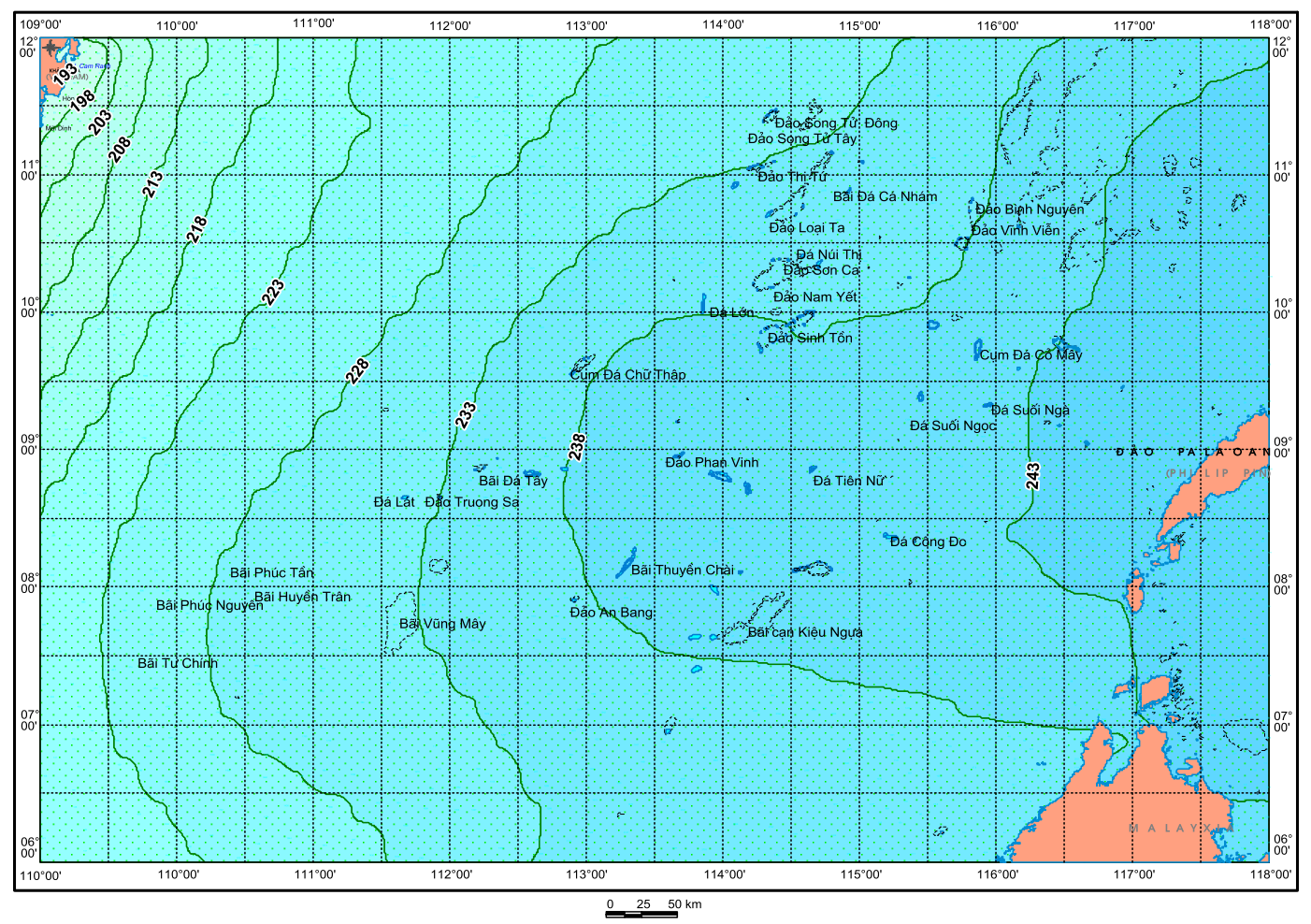

Hình 8. Phân bố sinh khối động vật nổi $\left(\mathrm{mg}\right.$-tươi $\left./ \mathrm{m}^{3}\right)$ tầng mặt trung bình tháng 1 
Nguyễn Ngọc Tiến, Dư Văn Toán

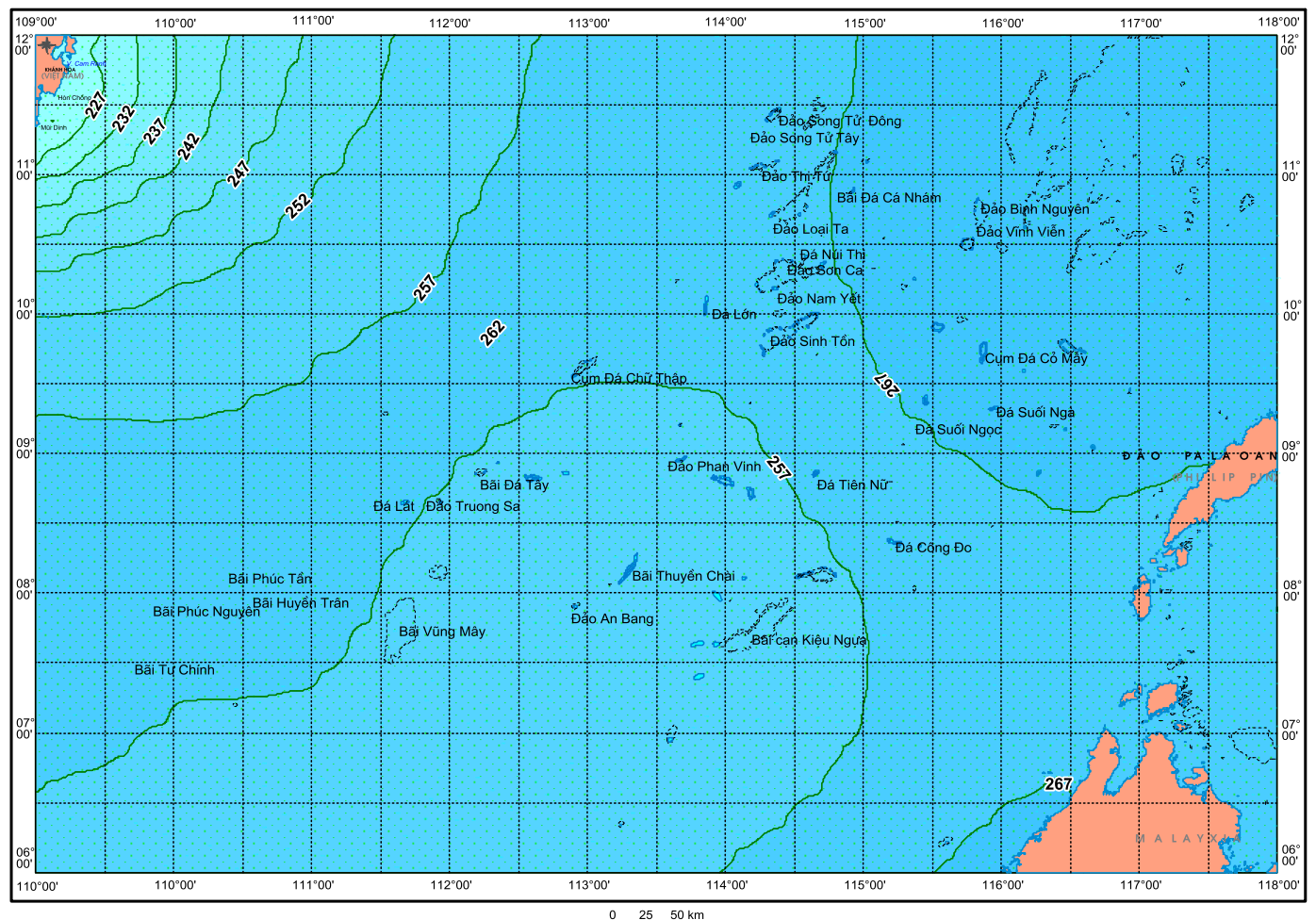

Hình 9. Phân bố sinh khối động vật nổi $\left(\mathrm{mg}\right.$-tươi $\left./ \mathrm{m}^{3}\right)$ tầng mặt trung bình tháng 7

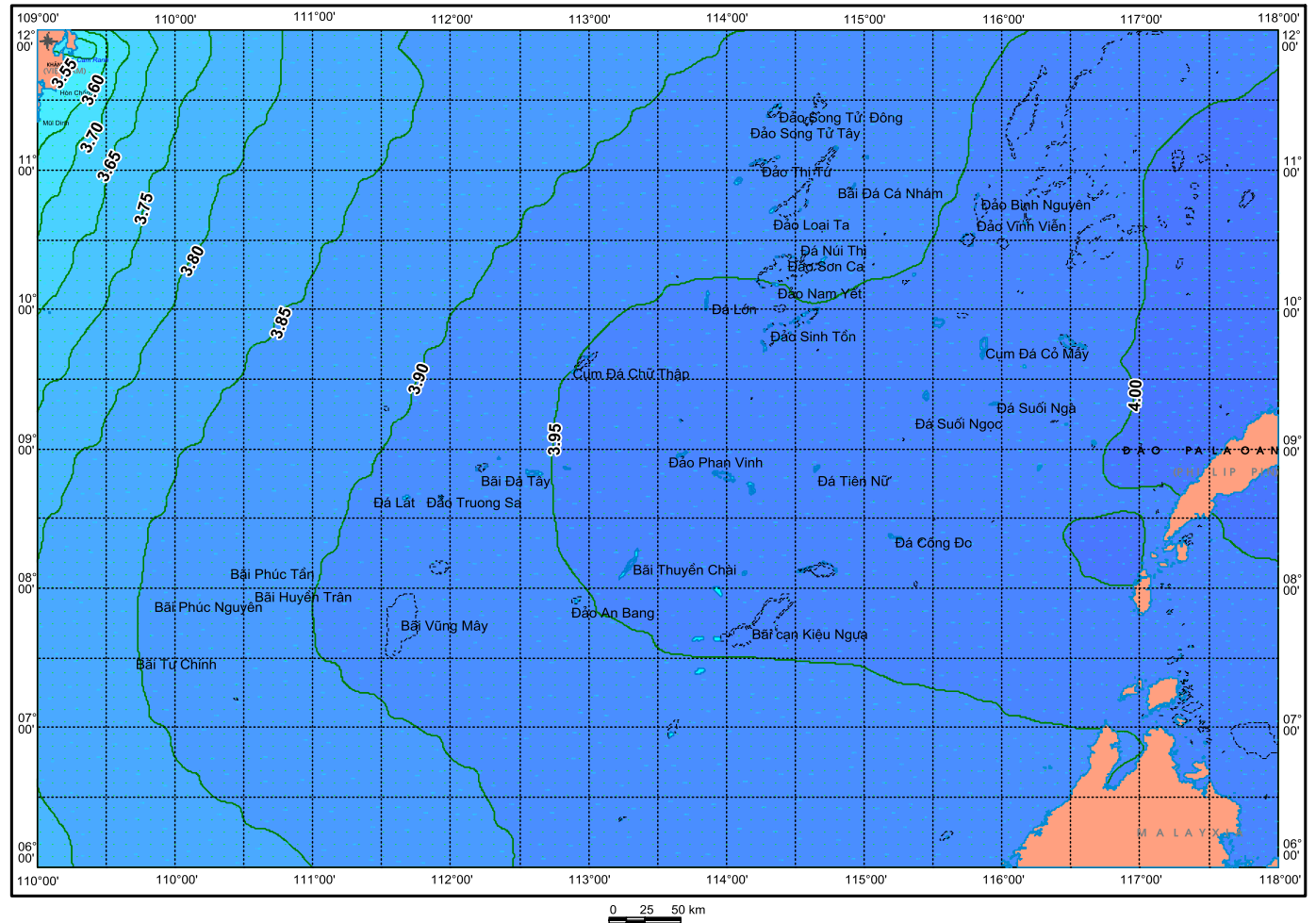

Hình 10. Phân bố năng suất thứ cấp $\left(\mathrm{mgC} / \mathrm{m}^{3} / \mathrm{ngày}\right)$ tầng mặt trung bình tháng 1 


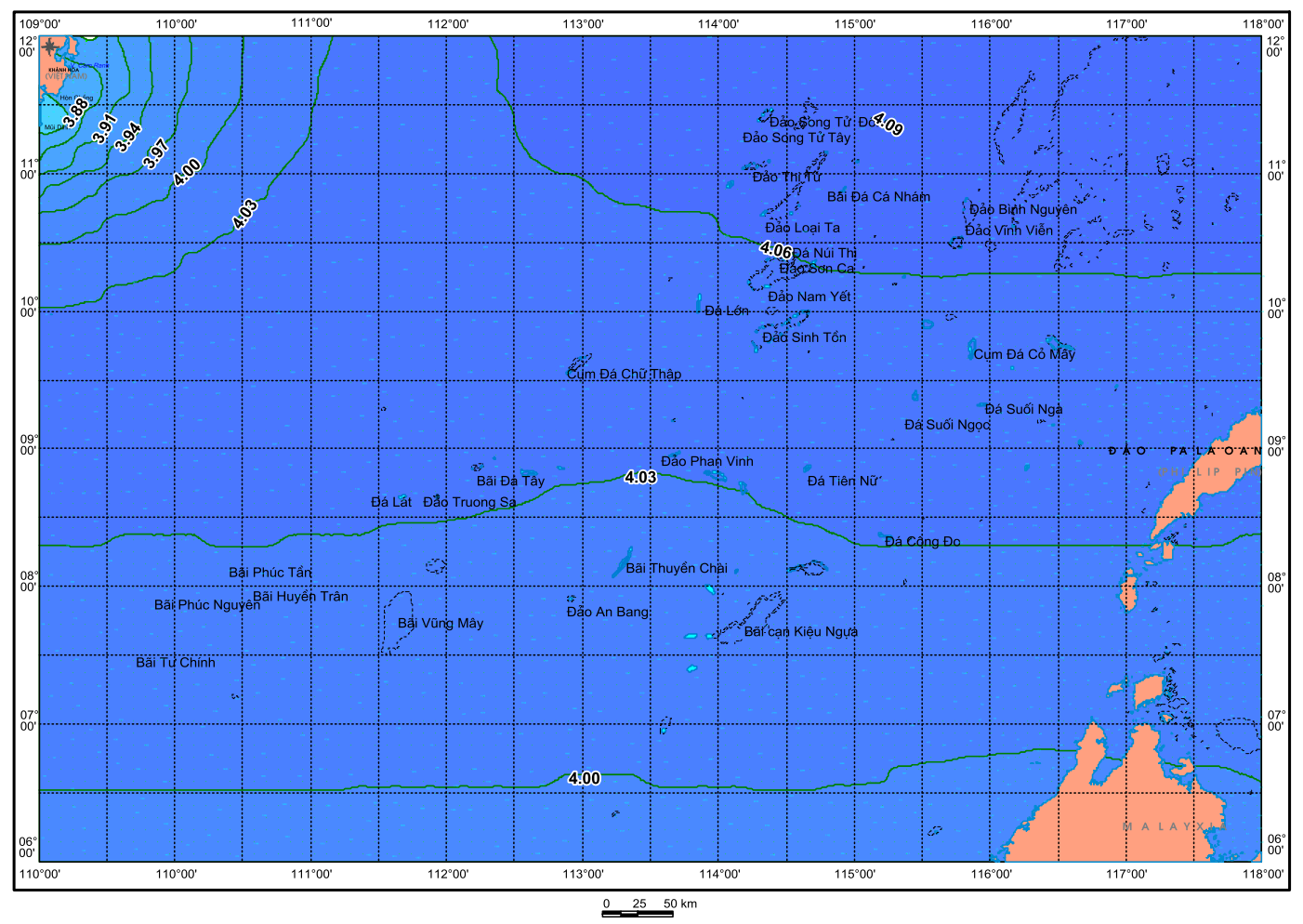

Hình 11. Phân bố năng suất thứ cấp $\left(\mathrm{mgC} / \mathrm{m}^{3} /\right.$ ngày) tầng mặt trung bình tháng 7

Năng suất thứ cấp trong mùa gió Đông Bắc thấp hơn trong mùa gió Tây Nam và cả hai mùa phân bố theo xu hướng tăng dần từ bờ ra khơi trên vùng biển nghiên cứu (hình 10 ). Trong mùa này hầu hết toàn vùng biển có năng suất thứ cấp trong khoảng 2,6 đến trên 4,0 $\mathrm{mgC} / \mathrm{m}^{3} /$ ngày. Vị trí các khu vực có năng suất thứ cấp cao trùng hợp tương đối với các khu vực có sinh khối cao.

Trong mùa gió Tây Nam tháng 7 (hình 11), năng suất thứ cẩp phân bố tương đối đồng đều và có giá trị trong khoảng 3,8-5,0 $\mathrm{mgC} / \mathrm{m}^{3} /$ ngày. Đây là sự khác biệt về giá trị năng suất thứ cấp giữa 2 mùa.Điều này phù hợp với đặc trưng của hệ sinh thái biển nhiệt đới Việt Nam, nơi có các yếu tố sinh thái môi trường biến đổi không nhiều trong năm.

\section{KẾT LUẬN}

Năng suất sinh học của quần xã Plankton vùng biển Trường $\mathrm{Sa}$ Việt $\mathrm{Nam}\left(6-12^{\mathrm{O}} \mathrm{N}, 109\right.$ $\left.118^{\mathrm{O}} \mathrm{E}\right)$ được tính toán trên cơ sở các hệ số chuyển hoá năng lượng giữa các bậc dinh dưỡng. Các hệ số này được tìm từ việc giải bài toán mô hình chu trình chuyển hoá Nitơ trong hệ sinh thái vùng biển nghiên cứu. Kết quả cho thấy rằng: năng suất sơ cấp tinh của vùng biển đạt cỡ 24 đến $28 \mathrm{mgC} / \mathrm{m}^{3} /$ ngày trong mùa gió Đông Bắc và mùa gió Tây Nam. Trong gió mùa Đông Bắc sinh khổi động vật nổi tầng mặt đạt giá trị trong khoảng $180-243 \mathrm{mg}$-tươi $/ \mathrm{m}^{3}$, trung bình $211 \mathrm{mg}$-tươi $/ \mathrm{m}^{3}$. Trong mùa gió Tây Nam sinh khối động vật nổi dao động trong khoảng 227 - $267 \mathrm{mg}$-tươi $/ \mathrm{m}^{3}$.

Năng suất thứ cấp của vùng biển biến đổi trong khoảng 3,6 đến $4,0 \mathrm{mgC} / \mathrm{m}^{3} /$ ngày, nhỏ hơn năng suất sơ cấp khoảng 100 lần. Năng suất thứ cấp trong mùa gió Đông Bắc và mùa gió Tây Nam phân bố tương đối đồng đều, xu hướng tăng dần từ bờ ra khơi trên vùng biển.

\section{TÀI LIỆU THAM KHẢO}

1. Nguyễn Tác An, 1977. Năng suất sinh học sơ cấp và hiệu ứng sinh thái của dòng nước trồi ở vùng biển Nam Trung Bộ, Các công trình nghiên cứu vùng nước trồi mạnh Nam Trung Bộ. Nxb. KH \& KT Hà Nội. Tr. 114-130. 
2. Doan Bo, Liana McManus and others, 1997. Primary productivity of phytoplankton in study area of RP-VN JOMSRE-SCS 1996. Proceedings: Conference on the PhilippinesVietnam Joint Oceanographic and Marine Scientific Research Expedition in the South China Sea 1996, Hanoi, 22-23 April 1997, pp. 72-86.

3. Đoàn Bộ, Nguyễn Dưong Thạo, 2001. Sinh vật phù $\mathrm{du}$ vùng biển phía Tây Trường $\mathrm{Sa}$ và mối quan hệ của chúng với các yếu tố môi trường. Tạp chí Thủy Sản, Số 6 .

4. Đoàn Bô̂, 2005. Một số kết quả tính toán năng suất sinh học của quần xã plankton vùng biển khơi nam Việt Nam. Tạp chí khoa học ĐHQG HN, Tập 21, Số 3AP. Tr. 1-7

5. Nguyễn Ngọc Tiến, 2011. Đánh giá quá trình sản xuất sơ cấp và hiệu quả sinh thái vùng biển vịnh Bắc Bộ. Tạp chí Khoa học và Công nghệ. Số đặc biệt. Tập 49, Số 6B.

6. Nguyễn Ngọc Tiến, Nguyễn Chí Công, Du Văn Toán, 2011. Mô hình chu trình chuyển hóa Ni tơ trong hệ sinh thái biển áp dụng cho vùng biển vịnh Bắc Bộ. Tạp chí Khoa học và Công nghệ biển. Tập 11, Số 4 .

7. World Ocean Atlas (WOA- Database), 2009. CD-Rom, NOAA. 


\title{
BIOLOGICAL PRODUCTION OF PLANKTON COMMUNITY IN THE MARINE REGION OF TRUONG SA ARCHIPELAGO
}

\author{
${ }^{1}$ Nguyen Ngoc Tien, ${ }^{2}$ Du Van Toan \\ ${ }^{1}$ Institute for Marine Geology and Geophysics-VAST \\ ${ }^{2}$ Vietnam Administration of Seas and Islands
}

\begin{abstract}
The biological production of plankton population in Truong Sa (Spratly) archipelago, Vietnam $\left(6-12^{\circ} \mathrm{N}, 109-118^{\circ} \mathrm{E}\right)$ was calculated basing on energy transformed coefficients between nutrient orders. These coefficients were found by solving Nitrogen transformed cycle model in researched marine region ecosystem. The results show that:

The coarse primary power is about $69 \mathrm{mgC} / \mathrm{m}^{3} /$ day in North-East monsoon and South-West monsoon, with about $40 \%$ fine product. Organic material synthesize ability in Southern research zone is higher than that in the Northern zone.

The fine primary power reaches from 24 to $28 \mathrm{mgCl} \mathrm{m}^{3} /$ day in North-East monsoon and SouthWest monsoon. The distribution of primary power is related to the temperature field of this marine region through seasons. The nature energy transformed coefficient is 2,5\%.

The secondary power changes in range 3,6-4,0 $\mathrm{mgC} / \mathrm{m}^{3} /$ day, less than 100 times primary power. The secondary power distributes relatively equal in North-East monsoon and South-West monsoon, which has the trend increasing slowly from shore to open sea.
\end{abstract}

Keywords: Community, biological, plankton 